\title{
АНАТОМИЧЕСКИЕ ОБОСНОВАНИЯ ФОРМИРОВАНИЯ И ПЕРЕМЕЩЕНИЯ НЕСВОБОДНЫХ КОСТНЫХ ТРАНСПЛАНТАТОВ НА КЛЮЧИЦЕ
}

\author{
(С Гайворонский И.В. ${ }^{1,3}$, Родионов А.А. ${ }^{3}$, Микитюк С.И. ${ }^{2}$, Горячева И.А. ${ }^{1,3}$, Ничипорук Г.И. ${ }^{1,3}$ \\ ${ }^{1}$ Кафедра нормальной анатомии, ${ }^{2}$ кафедра военно-полевой хирургии \\ Военно-медицинской академии им. С.М. Кирова, Санкт-Петербург; \\ ${ }^{3}$ кафедра морфологии Санкт-Петербургского государственного университета, Санкт-Петербург \\ E-mail: solnushko12@,mail.ru
}

\begin{abstract}
На основании изучения морфометрических характеристик ключицы взрослого человека, прикрепляющихся к ней мышц и питающих сосудов дано анатомическое обоснование возможности формирования несвободных костных трансплантатов на мышечно-сосудистой ножке в грудной и акромиальной частях ключицы и их перемещения в ее среднюю часть. Изучены минимальные, максимальные и средние значения основных параметров ключицы и мышечно-сосудистой ножки у взрослых мужчин и женщин. Установлены размеры несвободных костных трансплантатов ключицы, формируемых на основе грудной или дельтовидной ветвей грудоакромиальной артерии. Они составляют 3 см в длину, 0,4 см в толщину. Экспериментально доказана возможность перемещения данных трансплантатов в среднюю часть тела ключицы на расстояние до 5 см. Рекомендовано использование несвободных костных трансплантатов ключицы для лечения ложных суставов и костных дефектов средней части тела ключицы.
\end{abstract}

Ключевые слова: ключица, несвободный костный трансплантат, грудоакромиальная артерия, большая грудная мышца, дельтовидная мышца, анатомическое обоснование.

\section{ANATOMIC SUBSTANTIATION FOR FORMATION AND SHIFT OF NON-VASCULARIZED BONE GRAFTS ON CLAVICLE} Gaivoronsky I.V. ${ }^{1,3}$, Rodionov A.A. ${ }^{3}$, Mikityuk S.M. ${ }^{2}$, Goryacheva I.A. ${ }^{1,3}$, Nichiporuk G.I. ${ }^{1,3}$

${ }^{1}$ Department of Normal Anatomy, ${ }^{2}$ Department of Military Field Surgery of S.M. Kirov Military Medical Academy, St. Petersburg; ${ }^{3}$ Department of Morphology of St. Petersburg State University, St. Petersburg

On the basis of studying the morphometric characteristics of a clavicle of an adult, the muscles attached to it, and the feeding vessels we developed the anatomic substantiation for the possibility of non-vascularized bone graft formation on a musculovascular pedicle in the chest and acromial parts of a clavicle and its shift to the middle part. The minimum, maximum, and average values of key parameters of a clavicle and musculovascular pedicle in adult men and women were studied. The sizes of non-vascularized bone grafts of a clavicle which were formed on the basis of chest or deltoid branches of thoracoacromial artery were established. They made $3 \mathrm{~cm}$ long and $0.4 \mathrm{~cm}$ thick. The possibility of shifting these grafts to the middle part of a clavicle body up to $5 \mathrm{~cm}$ is experimentally proved. The use of non-vascularized bone grafts of a clavicle for treatment of nonunions and bone defects of the middle part of a clavicle body is recommended.

Keywords: clavicle, non-vascularized bone graft, thoracoacromial artery, pectoralis major muscle, deltoid muscle, anatomical substantiation.

Несмотря на широкое внедрение в травматологическую практику современных высокотехнологичных методик лечения переломов довольно часто наблюдаются различные нарушения консолидации костных отломков [4].

Учитывая возросшие технические возможности лечения нарушений консолидации переломов и дефектов костей, целесообразно использовать костные аутотрансплантаты [1, 13, 14]. В отечественной травматологии уже накоплен большой опыт как свободной, так и несвободной пластики кровоснабжаемыми костными трансплантатами [2, 10].

Применительно к верхней конечности известен целый ряд работ, касающихся формирования данных трансплантатов [8, 12]. Свободная пересадка кровоснабжаемых костных аутотрансплантатов требует специальной подготовки хирургов, использования дорогостоящего оборудования и инструментария, отличается высокой технической сложностью и большой длительностью микрохирургических операций [9, 11]. Достаточно частым осложнением таких операций является встречающийся в 5-18\% случаев тромбоз микрососудистых анастомозов [14].

При использовании несвободных костных аутотрансплантатов на сосудистой ножке указанные сложности и осложнения нивелируются. Их преимуществом является устойчивое кровоснабжение перемещенного комплекса тканей при общем уменьшении травматичности вмешательства и операционного времени. Вместе с тем следует отметить, что систематизированные данные о возможностях 
формирования несвободных костных трансплантатов ключицы отсутствуют [3].

В связи с этим целью данного исследования явились анатомические обоснования возможностей формирования и последующего перемещения несвободных костных трансплантатов на мышечно-сосудистой ножке в области ключицы.

\section{МАТЕРИАЛЫ И МЕТОДЫ ИССЛЕДОВАНИЯ}

Материалом исследования служили 60 костных препаратов ключицы, 30 полимернобальзамированных препаратов плечевого пояса взрослого человека с препарированными местами прикрепления к ключице большой грудной и дельтовидной мышц. На указанных препаратах изучали длину ключицы, длину и диаметр тела ключицы, протяженность мест прикрепления мышц. На 6 трупах взрослых людей в возрасте 44-59 лет, не имевших отклонений в физическом развитии, инъецировали сосудистое русло верхней конечности, препарировали сосуды и отрабатывали в эксперименте формирование костно-мышечно-сосудистых трансплантатов. Для контрастирования сосудов использовали смесь натурального латекса и черной туши в соотношении 5:1. Смесь вводили в подключичную артерию при помощи шприца Жане, соединенного с манометром и канюлей. Расход контрастного вещества составлял 70-75 мл при давлении не более 120 мм рт. ст. Препарирование сосудов проводили после застывания латекса (через 18 часов). Для этого применяли бинокулярную лупу ЛБВО-2 (производство Россия), с увеличением до 3,8 раза и микроскоп «KarlZeiss» (производство Германия) с увеличением до 24 раз. С помощью измерительных инструментов (линейка, штангенциркуль, микрометр) определяли размеры ключицы, мест прикрепления мышц, протяженность и диаметры

Проводили морфометрические исследования артерий, осуществляющих васкуляризацию ключицы в местах прикрепления к ней большой грудной и дельтовидной мышц, а также оценивали наибольшее возможное расстояние для перемещения трансплантата.

Для проведения экспериментальных оперативных вмешательств выделяли мышцу с идущими в ее составе сосудами к надкостнице ключицы. Затем с помощью осциллирующей пилы и долота формировали костный трансплантат прямоугольной формы толщиной на одну треть костной трубки донорской кости и длиной, соответствующей длине дефекта реципиентной кости. Сформированный трансплантат перемещали в дефект реципиентной кости и фиксировали спицами.

Полученные данные обработаны с использованием методов вариационной статистики. Для выявления значимости между средними величинами определялся критерий значимости Стьюдента (t). При достаточном суммарном числе наблюдений в сравниваемых группах статистическая значимость различия между из средними величинами признается значимой при $\mathrm{t}>2$.

\section{РЕЗУЛЬТАТЫ ИССЛЕДОВАНИЯ И ИХ ОБСУЖДЕНИЕ}

Размеры исследованных параметров ключицы отдельно для мужчин и женщин приводятся в таблице 1. Проведенные морфометрические исследования ключицы (30 женских и 30 мужских костных анатомических препаратов) свидетельствуют о наличии половых особенностей. При этом для всех без исключения изученных параметров ключицы у мужчин средние размеры оказались больше. Достоверные половые различия ( $<<0,05)$ выявлены для таких морфометрических характеристик, как длина ключицы и длина тела ключицы.

Полученные нами результаты исследований о морфометрических характеристиках ключицы и наличии половых различий совпадают с данными В.В. Кованова, А.А. Травина [7], согласно которым длина ключицы у мужчин в $62 \%$ случаев составляет 15-17 см, а у женщин она короче на 1-1,5 см. В нашем исследовании такие параметры ключицы, как длина и диаметр тела, размеры концов, являются оригинальными, данные о них в литературе отсутствуют.

Следующим этапом данного раздела работы явилось изучение морфометрических характеристик отдельных мышц плечевого пояса, используемых для формирования несвободных костно-мышечно-сосудистых трансплантатов. Нами изучена протяженность мест прикрепления к ключице большой грудной и дельтовидной мышц (см. табл. 1).

Приведенные в таблице 1 сведения о протяжённости мест прикрепления изученных мышц к ключице также свидетельствуют о наличии различий исследованных параметров у мужчин и женщин. Особое внимание необходимо обратить на протяженность линии прикрепления к передне-нижней поверхности ключицы большой грудной и дельтовидной мышц. 
Некоторые морфометрические характеристики ключицы и прикрепляющихся к ней мышц

\begin{tabular}{|c|c|c|c|c|}
\hline \multirow{2}{*}{ № } & \multirow{2}{*}{ Исследуемый параметр кости } & \multicolumn{2}{|c|}{ Средние размеры, мм } & \multirow{2}{*}{$\begin{array}{l}\text { t-критерий } \\
\text { Стъюдента }\end{array}$} \\
\hline & & мужчины & женщины & \\
\hline 1 & Длина ключицы & $142,6 \pm 5,6$ & $135,6 \pm 6,4$ & $2,19 *$ \\
\hline 2 & Длина тела ключицы & $107,8 \pm 6,6$ & $96,3 \pm 4,7$ & $2,27 *$ \\
\hline 3 & Диаметр грудинного конца ключицы & $18,3 \pm 1,3$ & $17,4 \pm 1,4$ & 1,60 \\
\hline 4 & Диаметр середины тела ключицы & $13,2 \pm 1,6$ & $12,0 \pm 1,6$ & 1,81 \\
\hline 5 & Размер акромиального конца ключицы & $20,2 \pm 1,3$ & $19,2 \pm 1,1$ & 1,42 \\
\hline 6 & $\begin{array}{l}\text { Протяженность прикрепления к ключице большой } \\
\text { грудной мышцы }\end{array}$ & $52,0 \pm 8,1$ & $48,3 \pm 11$ & 1,21 \\
\hline 7 & $\begin{array}{l}\text { Протяженность прикрепления к ключице дельтовидной } \\
\text { мышцы }\end{array}$ & $42,2 \pm 11$ & $38,4 \pm 8,2$ & 1,92 \\
\hline 8 & $\begin{array}{l}\text { Ширина полосы прикрепления к ключице большой } \\
\text { грудной мышцы }\end{array}$ & $4,3 \pm 1,0$ & $4,1 \pm 0,8$ & 1,15 \\
\hline 9 & $\begin{array}{l}\text { Ширина полосы прикрепления к ключице дельтовидной } \\
\text { мышцы }\end{array}$ & $5,2 \pm 1,2$ & $5,0 \pm 0,9$ & 1,12 \\
\hline
\end{tabular}

Примечание: * - морфометрические параметры, имеющие достоверные $(\mathrm{p}<0,05)$ половые различия.

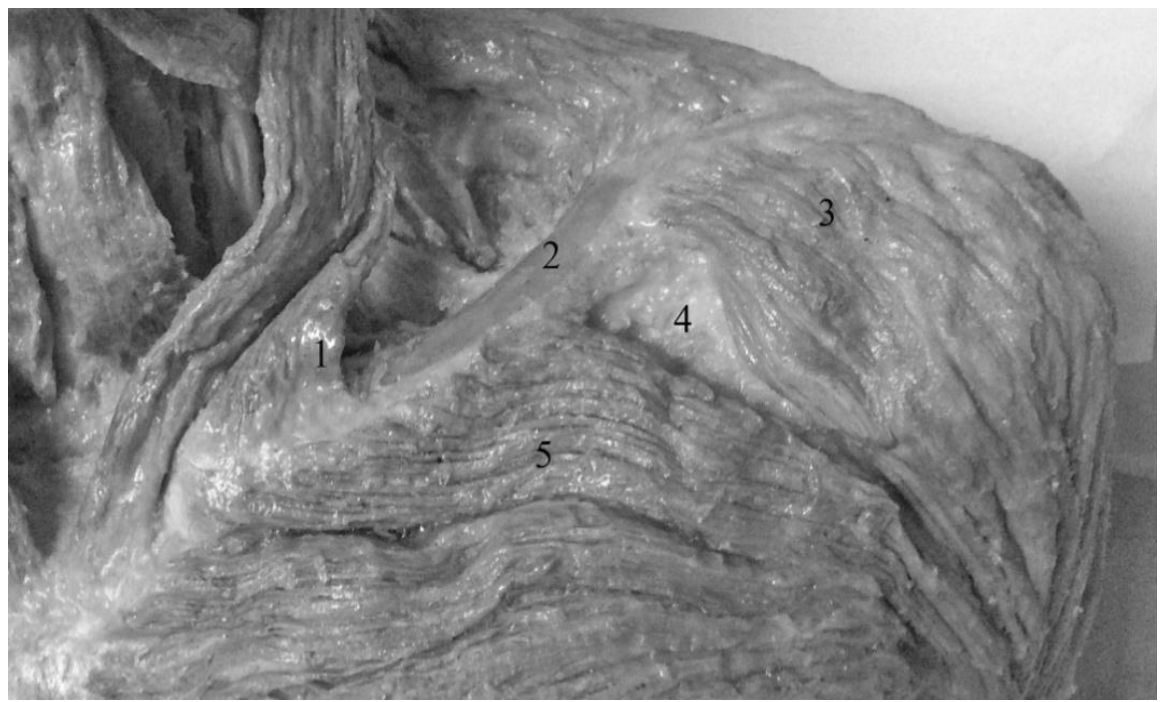

Рис. 1. Протяженность прикрепления ключичных частей дельтовидной и большой грудной мышц к переднее-верхней поверхности ключицы: 1 - грудиноключичнососцевидная мышца; 2 - ключица; 3 - ключичная часть дельтовидной мышцы; 4 - дельтовидно-ключичная борозда; 5 - ключичная часть большой грудной мышцы.

Как видно на рис. 1, между местами прикрепления этих мышц существует промежуток треугольной формы, который является продолжением дельтовидно-грудной борозды. В этой борозде как ориентир проходит головная вена, впадающая в подключичную вену. Ширина основания данного треугольника на теле ключицы составляет от 1 до 2 см. В его пределах прикрепление мышц отсутствует. Как указывает В.В. Кованов [5], под нижней поверхностью ключицы в пределах дельтовидно-грудного треугольника находится клетчатка. Следует обратить внимание, что к нижней поверхности ключицы на протяжении всей еe медиальной половины прилежат подключичные сосуды и пучки плече- вого сплетения, отграниченные лишь подключичной мышцей, а к латеральной половине клетчатка и клювовидно-ключичная связка. Указанные топографо-анатомические отношения необходимо учитывать при формировании костного трансплантата.

Одним из важных подготовительных этапов анатомического обоснования возможности формирования костных трансплантатов на ключице явилось изучение питающих артерий. Многие авторы называют множество источников васкуляризации ключицы, в частности, ветви грудоакромиальной, наивысшей межреберной, верхней грудной артерий и передних межреберных артерий из внутренней грудной артерии $[2,6]$. 


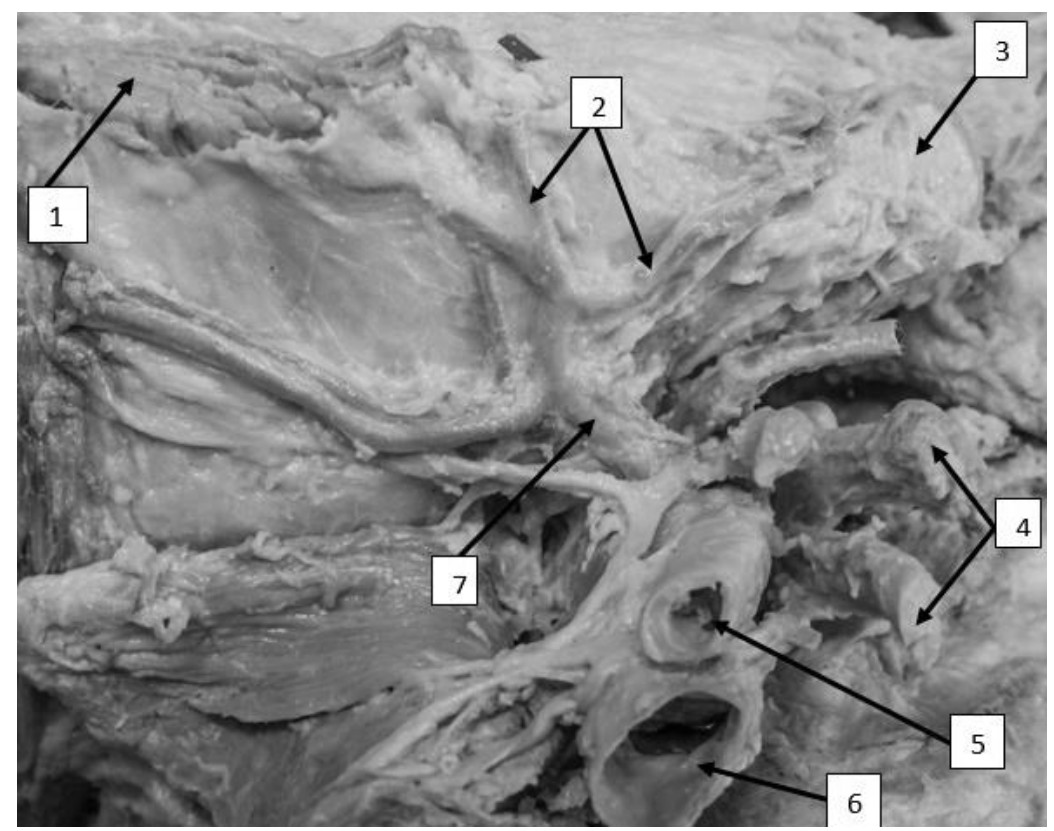

Рис. 2. Топография и архитектоника грудоакромиальной артерии и ее ветвей, кровоснабжающих большую грудную мышцу: 1 - большая грудная мышца; 2 - мышечные ветви грудоакромиальной артерии; 3 - ключица; 4 - ветви плечевого сплетения; 5 - подключичная артерия; 6 - подключичная вена; 7 - грудоакромиальная артерия.

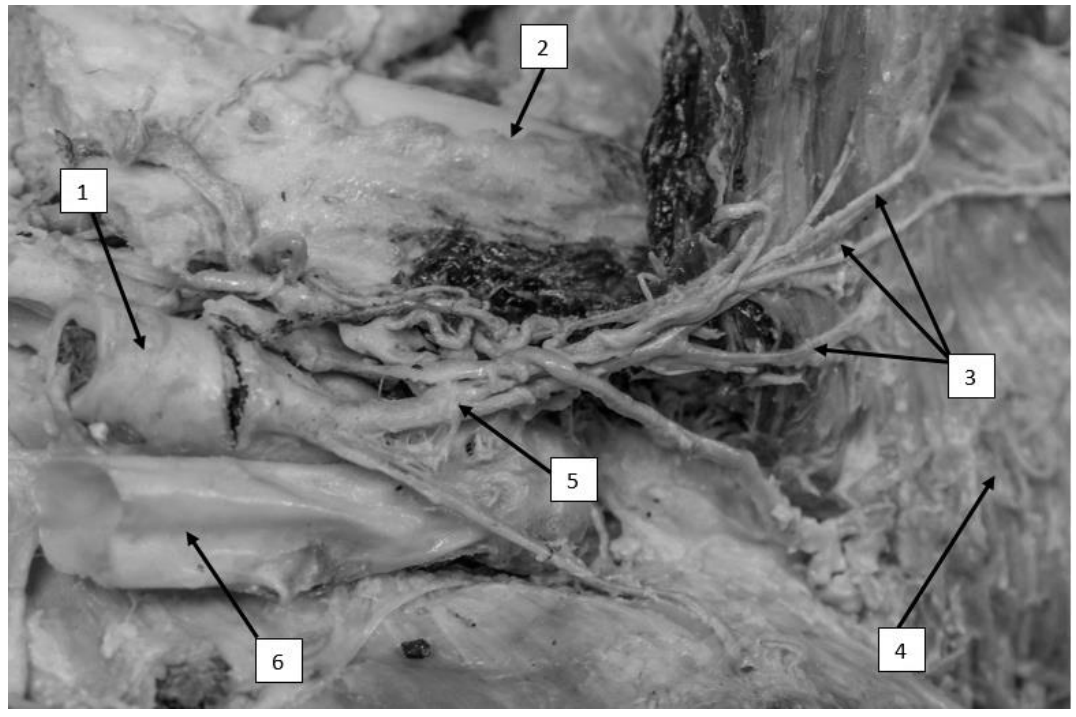

Рис. 3. Источники кровоснабжения дельтовидной мышцы в месте прикрепления к ключице: 1 - подмышечная артерия; 2 - ключица; 3 - мышечные ветви грудоакромиальной артерии к дельтовидной мышце; 4 - дельтовидная мышца; 5 - грудоакромиальная артерия; 6 - подмышечная вена.

Проведенные топографо-анатомические исследования позволили уточнить архитектонику и топографию грудоакромиальной артерии, которые имеют значение при формировании в зоне еe кровоснабжения костно-мышечных трансплантатов ключицы.

На изученном анатомическом материале грудоакромиальная артерия была обнаружена во всех $100 \%$ случаях. Она отходила от подмышечной артерии. Длина основного ствола артерии варьировала от 8 до 18 мм и в среднем составила $14 \pm 2,5$ мм. Диаметр варьировал от 2,5 до 4,5 мм и в среднем составил $3,4 \pm 0,5$ мм.
На всем протяжении грудоакромиальная артерия отдавала ветви к изучаемым мышцам плечевого пояса (большой грудной и дельтовидной мышце). Особое внимание при исследовании было уделено ее мышечным ветвям, подходящим к ключице в местах прикрепления большой грудной и дельтовидной мышц. Ветви грудоакромиальной артерии до вхождения в мышцу располагались на внутренней поверхности большой грудной и дельтовидной мышц, окруженные обильной прослойкой рыхлой соединительной ткани (рис. 2 и 3). Во всех 
наблюдениях рядом с артериями проходили соименные вены и ветви двигательных нервов.

Изучение с помощью микропрепарирования сосудов, проходящих внутри исследуемых мышц, показало, что артерии ориентированы параллельно волокнам мышечной ткани, а их концевые ветви достигают ключицы. Следовательно, кровоснабжение надкостницы ключицы происходит за счет постоянных мышечно-надкостничных ветвей грудной и дельтовидной ветвей грудоакромиальной артерии (табл. 2).

Диаметр надкостничных артерий варьировал от 0,4 до 0,6 мм (в среднем 0,5 $\pm 0,1$ мм). Диаметр сопутствующих вен всегда был несколько больше. Длина мышечно-надкостничных ветвей грудоакромиальной артерии от места отхождения до точки проникновения в надкостницу ключицы составляла от 7 до 11,5 мм, в среднем $10,1 \pm 0,8$ мм.

Проведенные исследования показали, что наиболее крупные и постоянные ветви грудоакромиальной артерии всегда проходят к ключице через прикрепляющиеся к ней мышцы большую грудную и дельтовидную. При этом через каждую из этих мышц в кортикальный слой ключицы проникают от двух до пяти артериальных ветвей диаметром от 0,2 до 0,6 мм (в среднем 0,3 $\pm 0,05$ мм). Сосудистое снабжение участков ключицы в местах прикрепления указанных мышц обеспечивает возможность формирования костно-мышечных трансплантатов ключицы на сосудистой ножке и их перемещения в несвободном варианте.

На втором этапе исследований, проведенных на бальзамированном и небальзамированном анатомическом материале, в зоне кровоснабжения грудоакромиальной артерии изучали возможности формирования и перемещения кровоснабжаемых участков ключицы в среднюю часть тела той же ключицы.

Выявленные анатомические особенности сосудистого снабжения ключицы ветвями грудоакромиальной артерии определили целесообразность формирования и клинического использования двух видов несвободных костномышечных трансплантатов:

- Костно-мышечный трансплантат акромиального конца тела ключицы;

- Костно-мышечный трансплантат грудного конца тела ключицы.

Моделирование разрабатываемой операции на небальзамированных препаратах осуществляли следующим образом. Ключицу обнажали продольным доступом по ее переднему краю. Далее, определив расположение и протяженность прикрепления большой грудной или дельтовидной мышц к ключице, находили ветви грудоакромиальной артерии и их надкостничные ветви с сопутствующими венами, формировали питающую ножку с включением в ее состав прослеженных надкостничных сосудов. Далее острым долотом формировали и выделяли фрагмент ключицы с прикрепляющейся к нему большой грудной или дельтовидной мышцей и идущей в толще мышцы питающей ветвью грудоакромиальной артерии. Затем мобилизовали костно-мышечный трансплантат и перемещали его в область предполагаемой реконструкции (рис. 4).

Установлено, что длина костного трансплантата может достигать 30 мм, а поперечный его размер не должен превышать одной трети толщины ключицы на соответствующем уровне (примерно 4 мм) из-за риска его перелома в месте выделения костного фрагмента. Несвободный костный трансплантат, сформированный на основе грудной ветви грудоакромиальной артерии, может быть перемещен на 4,0-5,5 см (в среднем на 4,6 \pm 0,8 см) к середине той же ключицы, а такой же трансплантат, сформированный на основе дельтовидной ветви той же артерии - на 4,5-6,0 см (в среднем на 5,5 $\pm 0,2$ см) (рис. 4).

Следует отметить, что на всех препаратах сосуды, доходя до надкостницы соответствующего участка ключицы, истончались до 200-300 мкм. Проникнув в надкостницу, артерии вначале анастомозировали друг с другом, затем их ветви через мелкие питательные отверстия проникали в кость.

Таблица 2

Вариантная анатомия артерий, васкуляризующих надкостницу ключицы

\begin{tabular}{|l|c|c|c|c|c|c|}
\hline \multirow{2}{*}{\multicolumn{1}{|c|}{ Изученные параметры }} & \multicolumn{3}{c|}{ Грудная ветвь } & \multicolumn{3}{c|}{ Дельтовидная ветвь } \\
& грудоакромиальной артерии & \multicolumn{2}{c|}{ грудоакромиальной артерии } \\
\cline { 2 - 9 } & $\min$ & $\max$ & $\mathrm{m} \pm \mathrm{mx}$ & $\min$ & $\max$ & $\mathrm{m} \pm \mathrm{mx}$ \\
\hline Длина сосудистой ножки (мм) & 38 & 55 & $46,1 \pm 8,3$ & 46 & 60 & $55,4 \pm 2,2$ \\
\hline $\begin{array}{l}\text { Диаметр сосудистой ножки в начальном } \\
\text { отделе (мм) }\end{array}$ & 1,9 & 2,7 & $2,3 \pm 0,5$ & 1,8 & 2,5 & $2,1 \pm 2,2$ \\
\hline Количество надкостничных ветвей (мм) & 2 & 4 & $3,2 \pm 0,4$ & 2 & 5 & $3,1 \pm 1,1$ \\
\hline Диаметр надкостничных ветвей (мм) & 0,2 & 0,6 & $0,3 \pm 0,03$ & 0,2 & 0,5 & $0,3 \pm 0,05$ \\
\hline
\end{tabular}




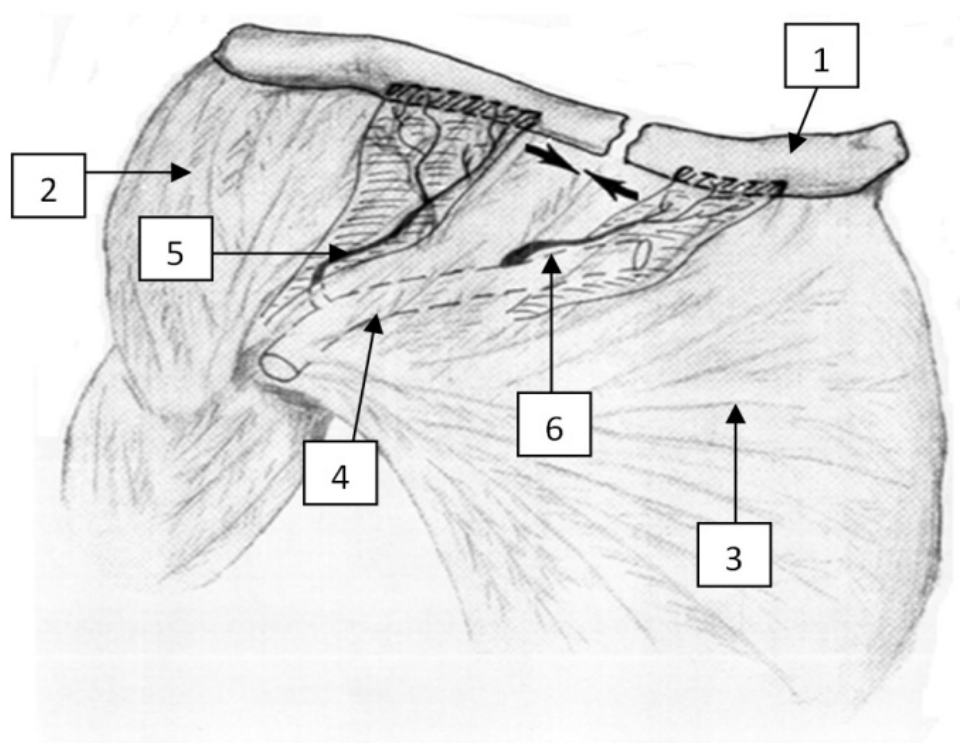

Рис. 4. Схема перемещения костных трансплантатов ключицы: 1 - ключица; 2 - дельтовидная мышца; 3 - большая грудная мышца; 4 - грудоакромиальная артерия; 5 - акромиальные ветви грудоакромиальной артерии; 6 - грудные ветви грудоакромиальной артерии.

Таким образом, несвободный костный трансплантат на мышечно-сосудистой ножке может быть сформирован как в области грудинной части тела ключицы (в месте прикрепления большой грудной мышцы), так и акромиальной части ее тела (в месте прикрепления дельтовидной мышцы). Источником васкуляризации обоих трансплантатов являются ветви грудоакромиальной артерии. Размер несвободного костного трансплантата ключицы составляет $30 \times 4$ мм. Данные трансплантаты могут быть перемещены в среднюю часть тела ключицы на расстояние до 50 мм.

Можно полагать, что анатомически обоснованные несвободные костные трансплантаты на мышечно-сосудистой ножке могут быть рекомендованы к использованию в клинической практике для лечения ложных суставов и дефектов средней части ключицы.

\section{ЛИТЕРАТУРА}

1. Белоусов А.E. Пластическая, реконструктивная и эстетическая хирургия. - СПб. : Гиппократ, 1998. $743 \mathrm{c}$.

2. Гайворонский И.В. Нормальная анатомия человека. Учебник для мед. вузов. - СПб. : СпецЛит, 2011. T. 2. - С. 205.

3. Гайворонский И.В., Микитюк С.И., Губочкин Н.Г. Анатомическое обоснование формирования несвободных костных трансплантатов на верхней конечности // Морфология. - 2014. - Т. 146, № 3. C. 69-74.

4. Гайдуков В.М. Ложные суставы. - СПб. : Наука, 1995. - $204 \mathrm{c}$.
5. Кованов В.В. Оперативная хирургия и топографическая анатомия. - М. : Медицина, 2003.400 c.

6. Кованов В.В., Аникина Т.И. Хирургическая анатомия артерий человека. - М. : Медицина, 1974. $360 \mathrm{c.}$

7. Кованов В.В., Травин А.А. Хирургическая анатомия верхних конечностей. - М. : Медицина, 1965. 559 c.

8. Родоманова Л.А. Первичная реконструкция первого пальца кисти // Травматология и ортопедия России. - 2005. - № 3. - С. 11-20.

9. Родоманова Л.А., Кочиш А.Ю. Реконструктивные микрохирургические операции при травмах конечностей. - СПб. : РНИИТО, 2012. - 116 с.

10. Шведовченко И.В., Голяна С.И., Орешков А.Б. Преимущества пластики дефектов костей кровоснабжаемыми аутотрансплантатами // Травматология и ортопедия России. - 2006. - № 2. - C. 80-81.

11. Han C.S., Wood M.B., Bishop A.T. Vascularized bone transfer // J. Bone Joint Surg. Am. - 1992. Vol. 74, N 10. - P. 1441-1449.

12. Hernandez-Cortes P., Elizondo-Esposito D., PenaRodrigues $C$. Acromial vascularised graft pedicled on the acromial branch of the thoracoacromial trunk for treatment of clavicular pseudoarthrosis // J. Shoulder Elbow Surg. - 2012. - Vol. 21, N 10. - P. 9-13.

13. Weiland A.G., Phillips T.W., Randolph M.A. Bone grafts: a radiologic, histologic and biomechanical model comparing autografts, allografts and free vascularised bone grafts // Plast. Reconstr. Surg. 1984. - Vol. 74, N 3. - P. 368-379.

14. Wood M.B. Upper extremity reconstruction by vascularized bone transfers: results and complications // J. Hand Surg. Am. - 1987. - Vol. 12, N 3. P. 422-427. 